\title{
Regulation of innate and adaptive immunity by Notch
}

\section{Freddy Radtke', H. Robson MacDonald ${ }^{2}$ and Fabienne Tacchini-Cottier ${ }^{3}$}

Abstract | Coordinated function of the innate and adaptive arms of the immune system in vertebrates is essential to promote protective immunity and to avoid immunopathology. The Notch signalling pathway, which was originally identified as a pleiotropic mediator of cell fate in invertebrates, has recently emerged as an important regulator of immune cell development and function. Notch was initially shown to be a key determinant of cell-lineage commitment in developing lymphocytes, but it is now known to control the homeostasis of several innate cell populations. Moreover, the roles of Notch in adaptive immunity have expanded to include the regulation of T cell differentiation and function. The aim of this Review is to summarize the current status of immune regulation by Notch. A better understanding of Notch function in both innate and adaptive immunity will hopefully provide multiple avenues for therapeutic intervention in disease.
'Ecole Polytechnique Fédérale de Lausanne, School of Life Sciences, Swiss Institute for Experimental Cancer Research, Lausanne, Vaud 1015, Switzerland. ${ }^{2}$ Ludwig Center for Cancer Research of the University of Lausanne, Epalinges 1066, Switzerland.

${ }^{3}$ Department of Biochemistry, WHO Immunology Research and Training Center, University of Lausanne, Epalinges 1066, Switzerland. e-mails: freddy.radtke@epfl.ch; HughRobson.Macdonald@ unil.ch; Fabienne.Tacchini-Cottier@ unil.ch doi:10.1038/nri3445

Published online 13 May 2013
Notch signalling is an evolutionarily conserved cell-to-cell communication cascade that was originally identified in flies ${ }^{1}$. Signalling is mediated by Notch ligand-receptor interactions between neighbouring cells. Flies have a single type I transmembrane-bound receptor that can be activated by two transmembranebound ligands named Serrate and Delta. Mammals possess four receptors (Notch 1-4) that are bound by five ligands of the Jagged family and Delta-like family (Jagged 1 and Jagged 2, and Delta-like ligand 1 (DLL1), DLL3 and DLL4). The biochemical details of the canonical Notch signalling cascade have been comprehensively reviewed $^{2,3}$ (BOX 1). In recent years, evidence has been found of non-canonical Notch signalling that does not require the RBPJ transcriptional mediator complex. These non-canonical signal transduction pathways may occur in the absence of receptor cleavage or through crosstalk with other signalling pathways (including the nuclear factor- $\kappa \mathrm{B}(\mathrm{NF}-\kappa \mathrm{B})$, transforming growth factor- $\beta$ $(\mathrm{TGF} \beta)$ and hypoxia-induced signalling pathways ${ }^{4-6}$.

Genome-wide expression and chromatin immunoprecipitation (ChIP) studies suggest the existence of a large number of genes that can be regulated by Notch ${ }^{7,8}$. Despite the large number of potential Notch target genes, the best-characterized are the basic helix-loophelix (bHLH) transcriptional repressors of the hairy enhancer of split (HES) and hairy-related (HRT) protein families 9 . As Notch signalling is recurrently either used for the generation and development of diverse blood cell lineages or used during peripheral immune responses following pathogenic infections, one of the major challenges is to identify the crucial driver target genes in these different settings in order to better understand how Notch exerts its pleiotropic functions.

The best-studied functions of Notch signalling in haematopoiesis are its essential roles during lymphocyte development, in particular during $\mathrm{T}$ cell lineage commitment and maturation in the thymus, and during marginal zone B (MZB) cell development in the spleen. More recently, Notch has also emerged as a key player in dendritic cell (DC) homeostasis and in the development of several lymphocyte subsets belonging to the innate immune system. In this Review, we discuss the role of Notch in the development of these specific blood lineages. Moreover, we highlight recent advances pertaining to Notch signalling in subsets of mature $\mathrm{CD}^{+}$and $\mathrm{CD} 8^{+} \mathrm{T}$ cells in peripheral lymphoid tissues.

\section{Developmental roles for Notch}

Notch signalling in T cell and MZB cell development. Bone marrow progenitors seed the thymus via the bloodstream, where they are instructed to adopt a T cell fate and further differentiate into $\alpha \beta$ T cells or $\gamma \delta \mathrm{T}$ cells before emigrating to the periphery. The first insights of Notch function in this context were derived from complementary genetic loss-of-function and gain-of-function studies. Inducible inactivation of Notch 1 or recombination signal binding protein for 


\section{Box 1 A brief overview of Notch signalling}

Mammals possess four Notch receptors (Notch 1-4) that are bound by five ligands of the Jagged, and Delta-like family (Jagged 1 and Jagged 2, and Delta-like ligand 1 (DLL1), DLL3 and DLL4). Newly synthesized receptors are proteolytically processed in the Golgi during their transport to the cell surface by a furin-like convertase. This results in the generation of heterodimeric receptors present at the cell surface (see the figure). Signalling is initiated by ligand binding to the receptors, which subsequently undergo two successive proteolytic cleavages; the first is mediated by disintegrin and metalloproteinase domain-containing protein (ADAM) family metalloproteinases at the extracellular S2 cleavage site close to the transmembrane domain. This results in the shedding of the extracellular part of the receptors, which are endocytosed by the ligand-expressing cell. This process requires monoubiquitylation of the cytoplasmic tail of the ligands by E3 ubiquitin ligases of the Mindbomb and Neuralized families. After a successful S2 cleavage and shedding of the extracellular domain, a last cleavage within the transmembrane domain is triggered by the $\gamma$-secretase activity of a presenilin multi-protein complex, thus liberating the Notch intracellular domain (NICD). This is a rate-limiting step during Notch activation, which can be pharmacologically blocked by small-molecule $\gamma$-secretase inhibitors ${ }^{112}$. Once the NICD is liberated, it translocates to the nucleus and binds to the transcription factors of the recombination signal binding protein for immunoglobulin $\mathrm{kJ}$ region (RBPJ) family (also known as CSL in humans, Suppressor of hairless in Drosophila melanogaster, and LAG-1 in Caenorhabditis elegans). When bound to RBPJ, the NICD recruits additional co-activators, including mastermind proteins (MAML1-3) and p300 in order to induce transcriptional expression of downstream target genes. Furthermore, Notch signalling is regulated at multiple levels. For example, Notch receptors undergo post-translational modifications by Fringe family glycosyltransferases. These transferases add $\mathrm{N}$-acetylglucosamine to $\mathrm{O}$-fucose residues present in certain epidermal growth factor (EGF) repeats of the extracellular domain of Notch receptors ${ }^{113}$. This influences the relative binding avidity of ligand-receptor pairs, which translates into different efficiencies or signalling strength of Notch receptors ${ }^{114-116}$.

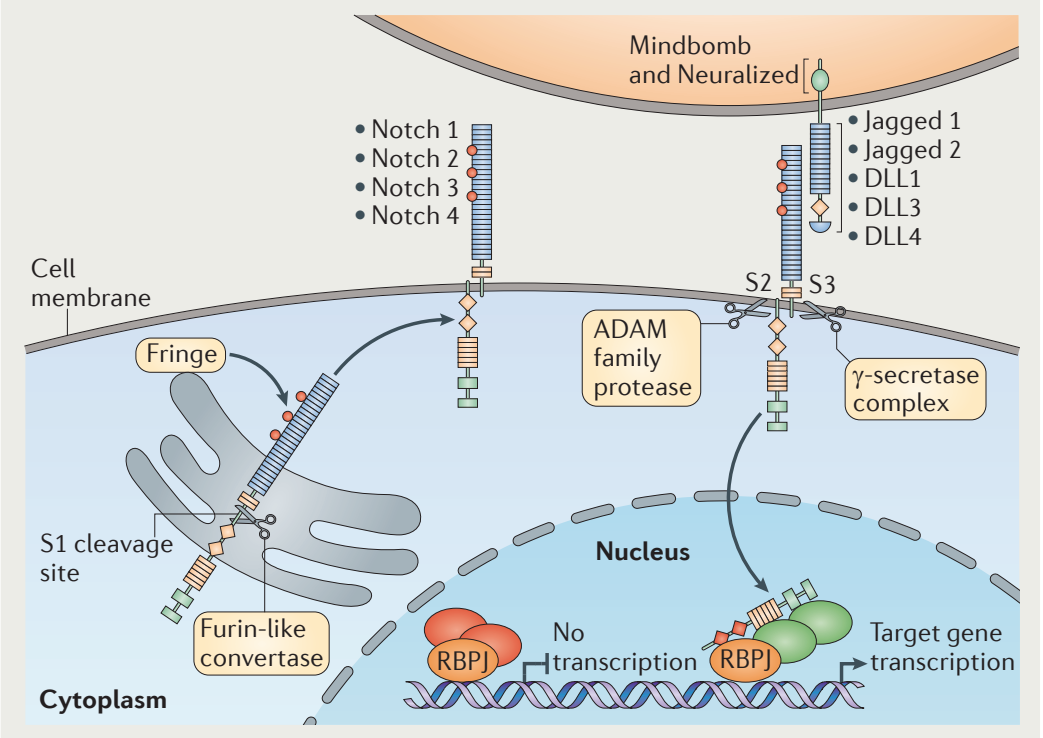

Proteins shown in red are co-repressors of RBPJ; those shown in green are cofactors for RBPJ. immunoglobulin $\kappa \mathrm{J}$ region (RBPJ; also known as CSL in humans) in bone marrow progenitors results in a complete block of $\mathrm{T}$ cell development, accompanied by the accumulation of ectopic B cells in the thymus ${ }^{10,11}$. By contrast, the constitutive expression of active forms of Notch induced ectopic T cell development and suppressed $\mathrm{B}$ cell development in the bone marrow ${ }^{12}$. Since then, multiple studies, including studies interfering with Notch signalling by transgenic expression of Notch modulators (such as Fringe proteins, Deltex 1 and Notchregulated ankyrin repeat-containing protein (NRARP)) or studies expressing dominant-negative forms of the transcriptional co-activator Mastermind-like protein 1 (MAML1), have confirmed the original findings ${ }^{13-16}$. This led to a model in which Notch 1 ensures T cell lineage commitment by inhibiting the other multiple cell-fate potentials of thymus-seeding cells, including myeloid cell and B cell potential, as well as conventional DC and plasmacytoid DC potential ${ }^{17-20}$ (FIG. 1). Although the transcription factor HES1 was recently shown to be an important Notch mediator for T cell lineage commitment, conditional inactivation of HES1 does not lead to the accumulation of B cells or DCs in the thymus ${ }^{21}$. This result suggests that Notch signalling specifies the $\mathrm{T}$ cell lineage through the activation of additional downstream target genes.

Although DLL1 and DLL4 can both instruct bone marrow cells to adopt a $\mathrm{T}$ cell fate in vitro, genetic ablation studies showed that in vivo the instructive signal is triggered through the interaction of Notch 1-expressing thymus-seeding cells with DLL4-expressing thymic epithelial cell ${ }^{22-26}$. Notch signalling is highest in immature $\alpha \beta \mathrm{T}$ cells (including in early thymic progenitors (ETPs), double-negative 2 (DN2) thymocytes and DN3a thymocytes) up to the DN3 stage, at which cells have to pass a critical checkpoint known as $\beta$-selection ${ }^{27}$. In these immature thymocytes, Notch 1 , but not HES1, is continuously required to restrict developing $\alpha \beta$ T cells to the $\mathrm{T}$ cell lineage ${ }^{21}$. However, once specified, $\gamma \delta \mathrm{T}$ cells are less dependent on Notch signalling, at least in the mouse. For human thymocytes the situation seems to be different, as $\gamma \delta$ T cells require higher levels of Notch signalling compared with developing $\alpha \beta \mathrm{T}$ cells ${ }^{28,29}$. After thymocytes successfully pass $\beta$-selection, they immediately downregulate Notch 1 expression, a process that is triggered by the pre-T cell receptor (preTCR)-mediated induction of the HLH transcription factor inhibitor of DNA binding 3 (ID3). ID3 inhibits E2A-induced transcription of Notch 1 (REF. 30). As a consequence, double-positive $\left(\mathrm{CD} 4^{+} \mathrm{CD} 8^{+}\right)$thymocytes have very low levels of Notch signalling, which is presumably required to avoid interfering with positive and negative selection in double-positive thymocytes, as well as to avoid the oncogenic properties of Notch signalling and its targets ${ }^{8}$ (FIG. 1).

Another well-established role for Notch signalling during lymphocyte development is its role in the specification of two different major subsets of splenic B cells, namely MZB cells and follicular zone B cells. Follicular zone $\mathrm{B}$ cells participate in $\mathrm{T}$ cell-mediated immune responses. These circulating B cells represent the majority of B cells within the spleen, where they localize to B cell follicles, hence the name follicular zone B cells. By contrast, MZB cells are found in the outer region of the splenic white pulp between the marginal sinus and the red pulp ${ }^{31}$. They are important in driving fast and vigorous T cellindependent antibody responses to blood-borne pathogens $^{32}$. Moreover, they express high levels of CD1d, thus allowing them to capture and present lipid antigens to invariant natural killer T cells. Both MZB cells and follicular 
RBPJ transcriptional mediator complex

This is the assembly of proteins including RBPJ (known as CSL in humans), the Notch intracellular domain (NICD) and transcriptional co-activators such as Mastermind-like proteins (MAMLS), histone acetyltransferases and the mediator complex in order to generate an active transcriptional complex on target promoters.

\section{$\beta$-selection}

During development, immature double-negative 3 thymocytes have to pass a critical checkpoint known as $\beta$-selection, or the pre-T cell receptor (pre-TCR) checkpoint, at which they have to signal via the pre-TCR to continue their development.

\section{Pre-T cell receptor}

(Pre-TCR). The pre-TCR consists of a productively re-arranged TCR $\beta$ chain associated with CD3 components and an invariant pre-TCRa chain.

\section{Invariant natural killer}

T cells

These are a specialized subset of innate-like lymphocytes that share properties of both natural killer (NK) cells and $T$ cells. They express

NK-related molecules and $T$ cell receptors (TCRs), and their TCRs recognize self and foreign lipids presented on CD1d molecules.

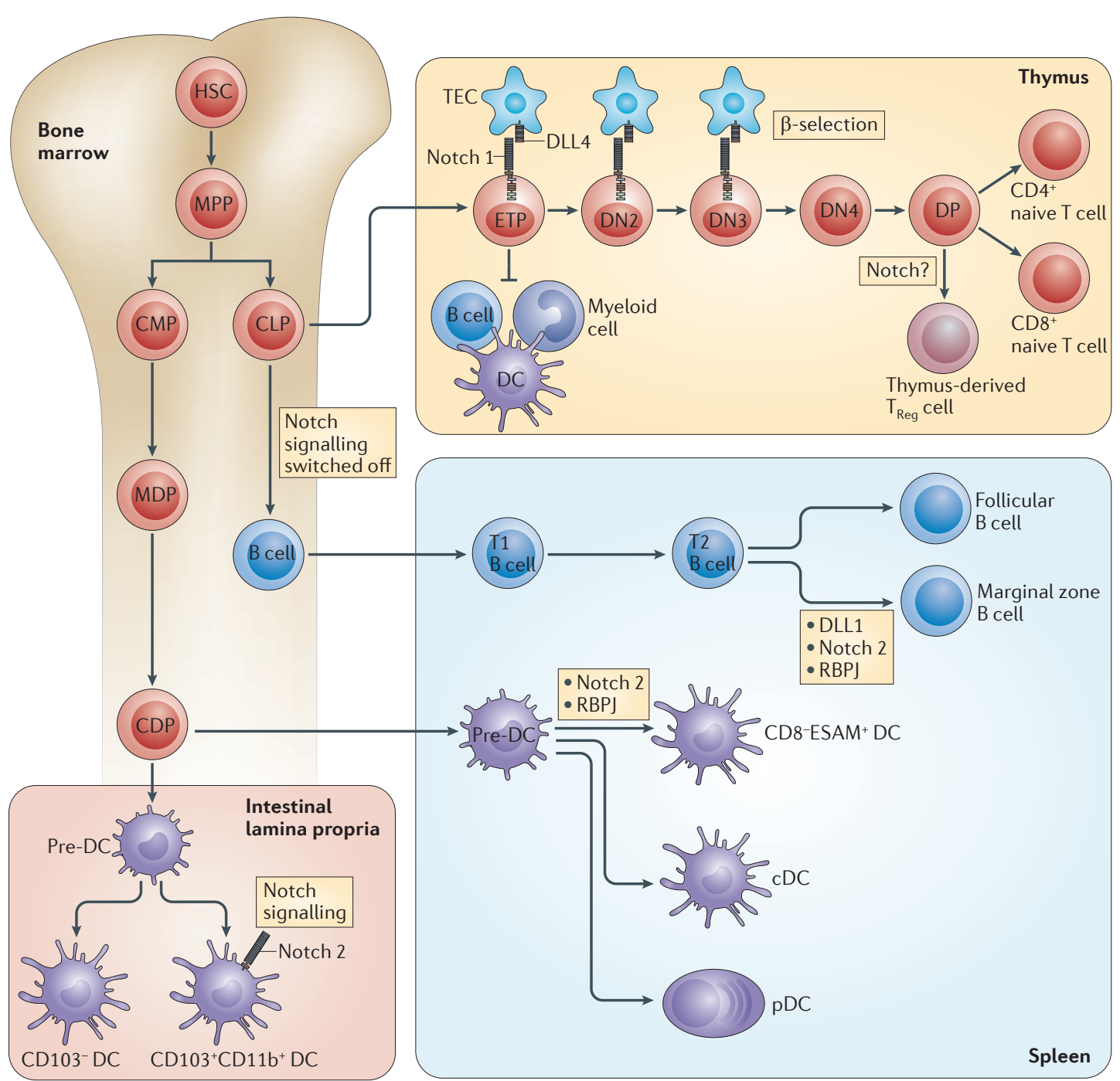

Figure 1 | Notch signalling in immune cell development. Bone marrow haematopoietic stem cells (HSCs) give rise to multipotent progenitors (MPPs) before differentiating into common myeloid progenitors (CMPs) and common lymphoid progenitors (CLPs). CLPs migrate from the bone marrow to the thymus, where thymic epithelial cells that express Delta-like ligand 4 (DLL4) trigger canonical Notch 1 signalling in early thymic progenitors (ETPs). This Notch 1 signal is essential for T cell lineage commitment and is further required during early phases of thymocyte differentiation up to the double-negative 3 (DN3) stage. Active Notch signalling during these early stages of T cell development inhibits other lineage potentials, such as B cell and myeloid cell (including dendritic cell (DC)) potential. During $\beta$-selection, Notch signalling is turned off as a consequence of pre-T cell receptor signalling. Thus subsequent stages of T cell development exhibit very low levels of Notch signalling. Notch was also suggested to influence the development of regulatory $T\left(T_{\text {Reg }}\right)$ cells (specifically, thymic $T_{\text {Reg }}$ cells). In bone marrow-residing CLPs, Notch signalling must be switched off to allow proper $B$ cell development. After migration of immature B cells to the spleen, interaction of DLL1 with Notch 2 (mediated by recombination signal binding protein for immunoglobulin $\mathrm{kJ}$ region (RBPJ)) induces Notch signalling in transitional $\mathrm{B}$ (T2) cells to specify marginal zone B cells as opposed to follicular B cells. The vast majority of DCs are derived from CMPs in the bone marrow, which give rise to macrophage-DC progenitors (MDPs). Subsequently, common DC progenitors (CDPs) develop into pre-DCs, seeding lymphoid and non-lymphoid organs via the bloodstream. In the spleen these pre-DCs are specified into multiple DC subsets, including classical DCs (cDCs) and plasmacytoid DCs (pDCs). Splenic CD8- endothelial cell-selective adhesion molecule $(E S A M){ }^{+} \mathrm{DCs}$ and $\mathrm{CD} 103^{+} \mathrm{CD} 11 \mathrm{~b}^{+} \mathrm{DC}$ in the lamina propria of the intestine require Notch signalling mediated by the Notch 2 receptor. DP, double-positive; TEC, thymic epithelial cell.

B cells originate from B cell progenitors in the bone marrow. When $\mathrm{B}$ cells migrate out of the bone marrow, they colonize secondary lymphoid organs, including the spleen, where they further mature through transitional stages (known as $\mathrm{T} 1$ and $\mathrm{T} 2$ ), before ultimately giving rise to mature follicular B cells or MZB cells in the spleen.
The specification process of T2 B cells into either of the two mature $\mathrm{B}$ cell fates is influenced by multiple factors ${ }^{31}$. However, conditional gene-targeting experiments of multiple Notch components revealed that the specification of MZB cells is strictly dependent on DLL1-mediated Notch 2 signalling (FIG. 1). Mice with conditional inactivation of 
DLL1 or Notch 2 have severely decreased numbers of MZB cells ${ }^{33,34}$, a phenotype that was also observed in RBPJmutant $^{35}$, MAML1-mutant ${ }^{\wedge 36,37}$, Mind bomb 1-mutant ${ }^{\wedge \wedge 38}$ and disintegrin and metalloproteinase domain-containing protein $10(\mathrm{ADAM} 10)^{39}$-mutant mice. Taken together, these genetic loss-of-function experiments strongly suggest that this process is mediated via canonical Notch signalling, although, surprisingly, HES1 is not required ${ }^{21}$. Inactivation of Msx2-interacting protein (MINT; also known as SPEN), which is a negative regulator of Notch signalling, resulted in increased MZB cell numbers ${ }^{40}$, which is an additional confirmation of Notch being an important regulator of MZB cell specification. Moreover, the cooperative action of two Fringe family members (Lunatic fringe and Manic fringe) seems to be necessary to strengthen the presumably weak interaction between MZB cell precursors and DLL1-expressing splenic niche cells ${ }^{41}$. Although it is clear that DLL1 is the non-redundant ligand that triggers a Notch 2 signal to specify MZB cells in the spleen, the nature of the DLL1-expressing cells is still unclear. Although non-haematopoietic cells ${ }^{33}$ and, in particular, endothelial cells have been shown to express DLL1 in the red pulp of the spleen ${ }^{41}$, it remains to be shown whether DLL1-expressing endothelial cells are indeed the splenic niche cells that support MZB cell development.

Notch signalling in DC development. DCs are a subset of haematopoietic cells that are specialized in antigen presentation. Until recently the only evidence for Notch involvement in DC differentiation was based on in vitro studies in which DC development could be influenced by the overexpression of Notch receptors or ligands and pharmacological manipulation by Notch inhibitors. More recently, loss-of-function studies have provided conclusive evidence that Notch signalling plays an important part in DC development and homeostasis. Conditional inactivation of RBPJ or Notch 2 specifically in DCs led to a selective reduction of a subset of DCs in the spleen but not in other lymphoid tissues ${ }^{42,43}$. Splenic DCs comprise a plasmacytoid DC compartment as well as several subsets of conventional DCs that can be identified by their differential expression of CD8 and CD11b, together with their expression of other markers, such as the adhesion molecule endothelial cell-selective adhesion molecule (ESAM). In the absence of Notch 2, only the CD8 ${ }^{-} \mathrm{CD} 11 \mathrm{~b}^{+} \mathrm{ESAM}^{+} \mathrm{DC}$ subset was missing, whereas other DC subsets (both conventional and plasmacytoid) were not affected ${ }^{43}$ (FIG. 1). The requirement for Notch 2 in the maintenance of splenic DCs seems to be non-redundant, as conditional inactivation of Notch 1 either in $\mathrm{DCs}^{43}$ or in all haematopoietic cells $s^{44,45}$ does not affect DC numbers.

The Notch ligand responsible for directing splenic DC development remains to be identified. However, it is noteworthy that the $\mathrm{CD} 8^{-} \mathrm{CD} 11 \mathrm{~b}^{+} \mathrm{ESAM}^{+} \mathrm{DC}$ subset that depends on Notch 2 signalling is localized to the splenic marginal zone in close proximity to stromal cells expressing DLL1 (REF. 42). As MZB cell development in the spleen is strictly dependent on DLL1-expressing stromal cells ${ }^{33}$ it is tempting to speculate that splenic DC development is likewise dependent on DLL1.
In addition to splenic DCs, a subset of DCs located in the lamina propria of the intestine is strongly reduced in the absence of Notch 2 . These DCs have a CD103 ${ }^{+} \mathrm{CD} 11 \mathrm{~b}^{+}$ phenotype and are believed to be specialized in antigen capture and transport to the mesenteric lymph nodes, where they can activate $\mathrm{CD} 4^{+}$helper T cells, and in particular those secreting interleukin-17 (IL-17): that is, T helper $17\left(\mathrm{~T}_{\mathrm{H}} 17\right)$ cells. Consistent with this model, $\mathrm{T}_{\mathrm{H}} 17$ cell numbers are also decreased in the intestine following DC-specific conditional inactivation of Notch 2 (REF. 43). Taken together, these recent studies reveal a novel and tissue-specific role for Notch 2 in the homeostasis of distinct DC subsets and consequent control of T cell priming (FIG. 1).

Notch signalling in innate lymphoid cell development. More recently, the development of another set of interesting immune cells, the innate lymphoid cells (ILCs), was reported to be influenced by Notch signalling. ILCs encompass a novel family of haematopoietic effector cells that have important functions in innate immune responses to infectious microorganisms, in the generation of secondary lymphoid organs and in tissue remodelling after tissue injury or infection. ILCs develop from common lymphoid progenitors, but unlike B cells and $\mathrm{T}$ cells they do not rearrange immunoglobulin genes or express antigen-specific receptors. In general they can be subdivided in three major subclasses (group 1, group 2 and group 3 ILCs), depending on whether they express $\mathrm{T}_{\mathrm{H}} 1$-type, $\mathrm{T}_{\mathrm{H}} 2$-type or $\mathrm{T}_{\mathrm{H}} 17$-type cytokines, respectively ${ }^{46,47}$. Whereas natural killer (NK) cells, which belong to the group 1 ILCs, have cytotoxic activity and functions, lymphoid tissue-inducer (LTi) cells (a type of group 3 ILC) are essential for the development and generation of secondary lymphoid organs. LTi cell development is dependent on retinoid-related orphan receptor- $\gamma \mathrm{t}(\mathrm{ROR} \gamma \mathrm{t})^{48}$. In this context, Notch signalling was shown to be transiently required for the generation of fetal $\alpha 4 \beta 7^{+}$LTi cell progenitors before upregulation of ROR $\gamma$ t. Subsequently, Notch signalling must be downregulated again to allow the expression of ROR $\gamma \mathrm{t}$ and the final maturation of LTi cells ${ }^{49}$.

More recent additions to the ROR $\gamma t$-dependent group 3 ILC subclass are IL-22-producing ILCs, which have been referred to as ILC22s and which share hallmarks of LTi cells and NK cells. The ILC22s are noncytotoxic but express the NK marker NKp46 and produce high levels of IL-22, and are therefore also known as NK22 cells. They are mostly found in mucosal tissues (such as the lamina propria of the intestine, Peyer's patches or tonsils) in humans and mice, where they induce early protective immune responses to colitis-inducing pathogens $s^{50,51}$. Both human and mouse ILC22s express the transcription factor aryl hydrocarbon receptor (AHR), which becomes activated by xenobiotics (that is, chemical compounds that are found in an organism but that are not normally produced by it, such as polycyclic aromatic compounds). On activation and ligand binding, AHR translocates from the cytoplasm to the nucleus and binds to promoter regions containing so-called xenobiotic response elements in order to induce target gene expression. 


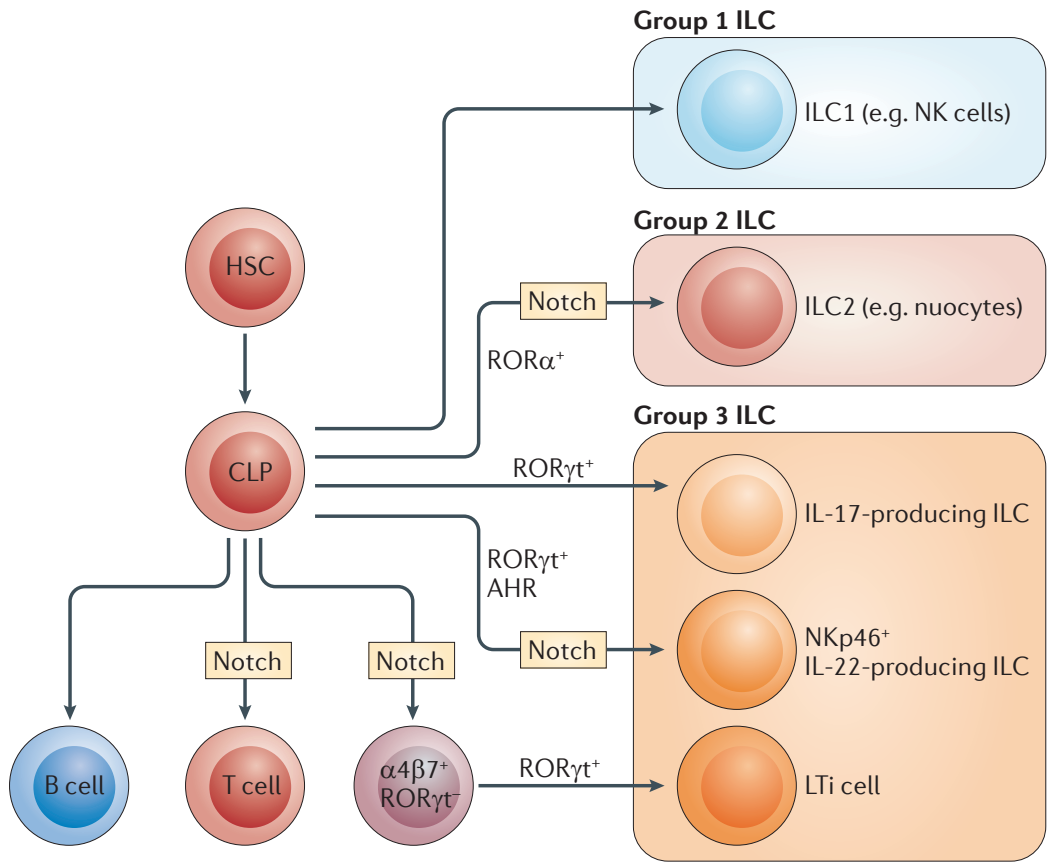

Figure 2 | The role of Notch signalling in the development of innate lymphoid cells. Haematopoietic stem cell (HSC)-derived common lymphoid progenitors (CLPs) give rise to adaptive immune cells, such as T cells and B cells, as well as to innate lymphoid cells (ILCs) that do not express antigen receptors. ILCs fulfil important functions in innate immune responses through their ability to generate and secrete different cytokines and/or to exhibit cytotoxic activity. They can be grouped into three major classes: group 1, group 2 and group 3 (REF. 47). ILCs diverge in their requirement for Notch (as indicated). AHR, aryl hydrocarbon receptor; IL, interleukin; LTi, lymphoid tissue-inducer; NK, natural killer; ROR, retinoid-related orphan receptor.

Interestingly, both $\mathrm{NOTCH} 1$ and $\mathrm{NOTCH} 2$ promoters contain such xenobiotic response elements, and expression of their transcripts is induced in vivo by the administration of an AHR ligand. Conditional inactivation of the transcription factor RBPJ, which mediates signalling downstream of all Notch receptors, resulted in a substantial reduction of NKp46 $6^{+}$ILCs in the lamina propria of the intestine but not in Peyer's patches. Similar results were obtained with $A h r$-mutant mice ${ }^{52,53}$, suggesting that the development and/or expansion of NKp46 $6^{+}$ILCs in certain microenvironments is mediated by AHR-induced Notch signalling ${ }^{54}$.

Another ROR $\gamma$ t-dependent but NKp46-negative subset of ILCs is mostly found in the colon of mice during inflammation. These cells express high levels of IL-17 in response to IL-23, which is responsible for gut pathology $^{55}$. Whether this particular subset of ILCs is also dependent on Notch is currently unknown.

Nuocytes, which are also known as ILC2s because of their ability to secrete high levels of type 2 cytokines, including IL-5 and IL-13, are RORa-dependent cells. They proliferate in response to IL-25 and IL-33 administration or in response to pathogens, including parasitic helminths, viruses and fungi ${ }^{56-58}$. They have an important role in type 2-mediated immunity. For example, activation of these cells by the administration of IL-25 is sufficient to clear parasitic worms even in the absence of adaptive immunity ${ }^{57}$. In vivo, common lymphoid progenitor (CLP) reconstitution assays revealed that nuocytes are derived from CLPs in the bone marrow. However, they can also be generated in vitro under appropriate culture conditions. CLPs, along with DN1 and DN2 thymocytes, develop into nuocytes when cultured on DLL1-expressing OP-9 cells in the presence of IL-7 and IL-33. In the absence of DLL1-mediated Notch signalling, these progenitors develop into B cells, suggesting that Notch signalling is required at least for the in vitro generation of nuocytes. It remains to be investigated whether the in vivo development or expansion of these cells is also dependent on or influenced by Notch signalling. Although DN1 and DN2 thymocytes retain the potential to develop into nuocytes in vitro, forkhead box N1 (FOXN1) ${ }^{\mathrm{nu} / \mathrm{nu}}$ mice (which lack a thymus) have normal nuocyte numbers; this indicates that in vivo these cells are likely to develop at extrathymic sites, such as the bone marrow ${ }^{58}$.

Taken together, these studies reveal that Notch signalling can influence the development and/or expansion of certain subsets of ILCs, which is probably also microenvironment dependent (FIG. 2). Future studies will be necessary to more specifically address the in vivo requirements and specific receptor-ligand interactions that are necessary for the development and function of certain ILC subsets.

\section{Notch and helper $\mathrm{T}$ cell functions}

During immune responses, naive $\mathrm{CD} 4^{+} \mathrm{T}$ cells encounter antigens in peripheral lymphoid organs. Recognition of cognate peptide antigens presented by antigen-presenting cells (APCs) triggers clonal T cell expansion and their differentiation into several functionally distinct $\mathrm{CD} 4^{+} \mathrm{T}_{\mathrm{H}}$ cell subsets. Each $\mathrm{T}_{\mathrm{H}}$ cell subset secretes a specific pattern of effector cytokines that coordinates immune responses against various types of pathogens and also has an important role in autoimmune inflammatory diseases. The most well-characterized $\mathrm{T}_{\mathrm{H}}$ cell subsets include $\mathrm{T}_{\mathrm{H}} 1$ cells, $\mathrm{T}_{\mathrm{H}} 2$ cells ${ }^{59}, \mathrm{~T}_{\mathrm{H}} 17$ cells $^{60,61}$ and regulatory $\mathrm{T}\left(\mathrm{T}_{\mathrm{Reg}}\right)$ cells ${ }^{62}$, as well as the more recently described $\mathrm{T}_{\mathrm{H}} 9$ cells ${ }^{3,64}$ and follicular $\mathrm{T}$ helper $\left(\mathrm{T}_{\mathrm{FH}}\right)$ cells $\mathrm{s}^{65,66}$. Although these $\mathrm{T}_{\mathrm{H}}$ cell subsets were long thought to be fixed lineages, some plasticity in the pattern of cytokines that they secrete may occur during the course of infection, a process that would allow a specific $\mathrm{T}_{\mathrm{H}}$ cell subset to react to changing environmental conditions $s^{67,68}$. Among the several factors contributing to the differentiation of naive $\mathrm{CD} 4^{+} \mathrm{T}$ cells towards a given $\mathrm{T}_{\mathrm{H}}$ cell subset, accumulating data indicate a crucial role for Notch signalling. However, the mechanisms involved have been somewhat controversial ${ }^{69-71}$. We discuss below recent advances in our understanding of the role for Notch in the differentiation and/or function of $\mathrm{CD} 4^{+} \mathrm{T}_{\mathrm{H}}$ cells.

Role of Notch ligands in $T_{H}$ cell differentiation and function. The induction of specific Notch ligands by pathogen-derived signals has a profound impact on the differentiation or function of CD4 ${ }^{+} \mathrm{T}$ helper cells. A correlation between the type of Notch ligand expressed on APCs and the development of $\mathrm{T}_{\mathrm{H}} 1$ and $\mathrm{T}_{\mathrm{H}} 2$ cells was first reported by Flavell and colleagues ${ }^{72}$ and further extended by different groups to these and other $\mathrm{T}_{\mathrm{H}}$ cell 
subsets. Studies carried out both in vitro and in vivo convincingly showed that the engagement of Delta-like Notch ligands favours the development of interferon- $\gamma$ (IFN $\gamma$ )-secreting $\mathrm{T}_{\mathrm{H}} 1$ cells, whereas the engagement of Jagged ligands preferentially induces the development of $\mathrm{T}_{\mathrm{H}} 2$ cells and $\mathrm{T}_{\text {Reg }}$ cells (reviewed in detail in REFS 71,73). The type of Notch ligands involved in the differentiation of other $\mathrm{T}_{\mathrm{H}}$ cell populations awaits further studies.

The impact of Notch on $T_{H} 1$ cell function in vivo. The impact of Notch receptor triggering on $\mathrm{T}_{\mathrm{H}}$ cell differentiation or function was first investigated using well-defined in vitro $\mathrm{T}_{\mathrm{H}}$ cell polarization conditions.

The numerous studies performed did not provide conclusive evidence for a role for Notch signalling during $\mathrm{T}_{\mathrm{H}}$ cell differentiation ${ }^{69,71}$. The importance of Notch signalling on $\mathrm{T}_{\mathrm{H}}$ cell differentiation or function is better documented by an increasing number of studies carried out in vivo.

The role of Notch in the differentiation of IFN $\gamma$ secreting $\mathrm{T}_{\mathrm{H}} 1$ cells in vivo has been investigated using several approaches designed to inhibit Notch signalling. Treatment of mice with $\gamma$-secretase inhibitors impeded disease progression in $\mathrm{T}_{\mathrm{H}} 1$ cell-mediated experimental autoimmune encephalomyelytis (EAE $)^{74,75}$. It was hypothesized that Notch 1 could bind to an RBPJ-binding sequence on the T-box 21 (Tbx21) gene promoter, which encodes T-bet, the master regulator of $\mathrm{T}_{\mathrm{H}} 1$ cell differentiation $^{74}$; however, such binding of Notch to the $T b \times 21$ gene was not confirmed in another study ${ }^{76}$. Targeting $\gamma$-secretase may not only affect Notch cleavage but may also affect the cleavage of many other targets that could affect $T_{H}$ cell differentiation independently of Notch signalling, emphasizing the importance of using various experimental approaches to block Notch signalling. In contrast to the results obtained following $\gamma$-secretase treatment, functional $\mathrm{T}_{\mathrm{H}} 1$ cells could develop in response to infection in mice that do not activate RBPJ because of dominant-negative MAML expression ${ }^{77}$. In the same line, mice deficient for RBPJ expression in their T cells were also able to mount a protective $\mathrm{T}_{\mathrm{H}} 1$ cell response following infection with the parasite Leishmania major ${ }^{78}$. Altogether, these studies suggest that $\mathrm{T}_{\mathrm{H}} 1$ cell differentiation does not involve canonical Notch signalling, defined as the association of the Notch intracellular domain (NICD) with RBPJ in the nucleus. Several partners could interact with Notch during non-canonical signalling in peripheral T cells. Subunits of the NF- $\kappa \mathrm{B}$ transcription factor were identified as potential Notch partners ${ }^{79,80}$, and further research is needed to characterize the interactions of Notch with NF-kB (FIG. 3a).

To further study the impact of Notch on $\mathrm{T}_{\mathrm{H}}$ cell differentiation, Notch receptors were inactivated by genetic deletion in $\mathrm{T}$ cells or were blocked using monoclonal antibodies directed against Notch 1 or Notch 3. In a model of passively transferred EAE, the adoptive transfer of lymph node cells treated with Notch 3-specific neutralizing antibodies, but not with Notch 1-specific neutralizing antibodies, reduced the release of IFN $\gamma$ and IL- 17 by myelin-reactive cells, with a corresponding decrease in the EAE disease scores ${ }^{75}$. Of note, it was not possible to determine in this study whether the lower levels of IFN $\gamma$ produced resulted from impaired $\mathrm{T}_{\mathrm{H}} 1$ cell differentiation and/or from impaired $\mathrm{T}_{\mathrm{H}} 1$ cell function.

Expression of Notch 1 (and compensatory expression of Notch 2 in the absence of Notch 1) on T cells is crucial for the differentiation of functional IFN $\gamma$-secreting $\mathrm{T}_{\mathrm{H}} 1$ cells during infection with L. major. Following parasite inoculation, Notch-deficient naive $\mathrm{CD} 4^{+} \mathrm{T}$ cells differentiated into $\mathrm{T}_{\mathrm{H}} 1$ cells expressing Tbx21 mRNA and IFN $\gamma$ proteins, but these cells were unable to secrete IFN $\gamma^{78}$ (FIG. 3a). These data suggest that Notch signalling is involved in the control of $\mathrm{T}_{\mathrm{H}} 1$ cell effector functions, rather than in the differentiation of $\mathrm{T}_{\mathrm{H}} 1$ cells. Thus, Notch 1, Notch 2 and Notch 3 have each been individually shown to affect the functions of $\mathrm{T}_{\mathrm{H}} 1$ cells in vivo, and it is possible that different Notch receptors may be involved in different $\mathrm{T}_{\mathrm{H}}$ 1-type contexts.

The impact of Notch on $T_{H} 2$ cell differentiation in vivo. Regulation of $\mathrm{T}_{\mathrm{H}} 2$ cell differentiation in vivo by Notch was documented in several experimental models ${ }^{81,82}$. In contrast to what was reported in $\mathrm{T}_{\mathrm{H}} 1$ cell differentiation, Notch signalling in $\mathrm{T}_{\mathrm{H}} 2$ cell differentiation was shown to be dependent on RBPJ (canonical Notch signalling). Several RBPJ-binding sites were identified on the Il4 enhancer (conserved non-coding sequence 2 (CNS2); also known as HS5), suggesting a direct role of Notch in IL-4 transcription in $\mathrm{T}_{\mathrm{H}} 2$ cells, NKT cells and possibly other IL-4-secreting cells ${ }^{72,82}$. As IL-4 is a master regulator of $\mathrm{T}_{\mathrm{H}} 2$ cell differentiation, Notch signalling may thereby promote $\mathrm{T}_{\mathrm{H}} 2$ cell differentiation by both cell-intrinsic and cell-extrinsic mechanisms. In addition to its direct regulation of Il4, Notch was reported to bind to the promoter of GATA-binding factor 3 (GATA3), a master regulator of $\mathrm{T}_{\mathrm{H}} 2$ cell differentiation ${ }^{83}$, thus inducing the expression of the Gata3 exon 1a transcript ${ }^{83}$. Both Notch 1 and RBPJ were shown to bind close to the Gata3 promoter, and GATA3 activity was required for the Notch-dependent induction of IL-4, suggesting a synergy between both pathways $^{76,81}$. Expression of GATA3 from the exon $1 \mathrm{~b}$ transcript was shown to be independent of Notch. The conditions determining the selective usage of either GATA3 exon 1a or exon $1 \mathrm{~b}$ transcripts and the need for Notch in $\mathrm{T}_{\mathrm{H}} 2$ cell differentiation remain to be defined and are likely to be context dependent (FIG. 3b).

The impact of Notch on other $T_{H}$ cell subsets in vivo. The Notch signalling pathway was also shown to cooperate with TGF $\beta$ to induce $\mathrm{T}_{\mathrm{H}} 9$ cells ${ }^{84}$. Interaction between SMAD3, a TGF $\beta$ target protein, and RBPJ resulted in the induction of the IL-9 promoter. Mice deficient in Notch 1 and Notch 2 in their T cells developed milder EAE compared with control mice, and both IL-9 and IL-17 cytokine production was decreased upon antigenic re-stimulation in vitro. This suggested that Notch signalling is regulating $\mathrm{T}_{\mathrm{H}} 9$ cell function during EAE. However, although the impact of Notch signalling on EAE is well documented, it is difficult to evaluate the impact of Notch on individual $\mathrm{T}_{\mathrm{H}}$ subsets during EAE owing to the plasticity among $T_{H}$ subsets $\left(T_{H} 17, T_{H} 1, T_{H} 9\right.$ and $\mathrm{T}_{\mathrm{Reg}}$ cells) that develops during the disease ${ }^{85}$. 
a $\mathrm{T}_{\mathrm{H}} 1$ cell differentiation

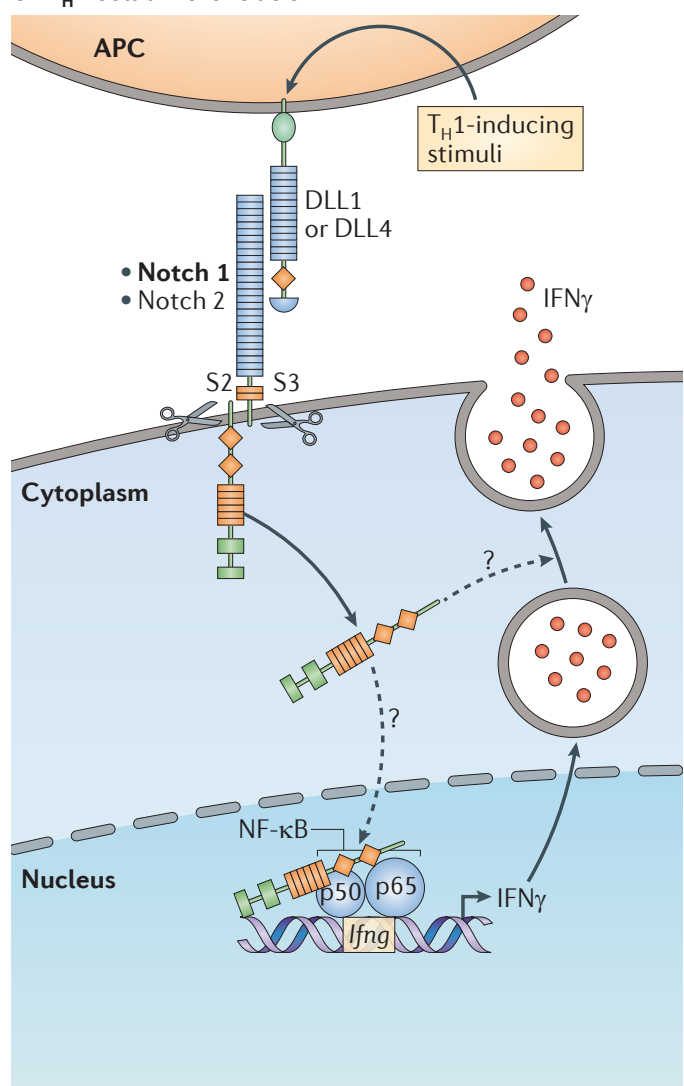

b $\mathrm{T}_{\mathrm{H}} 2$ cell differentiation

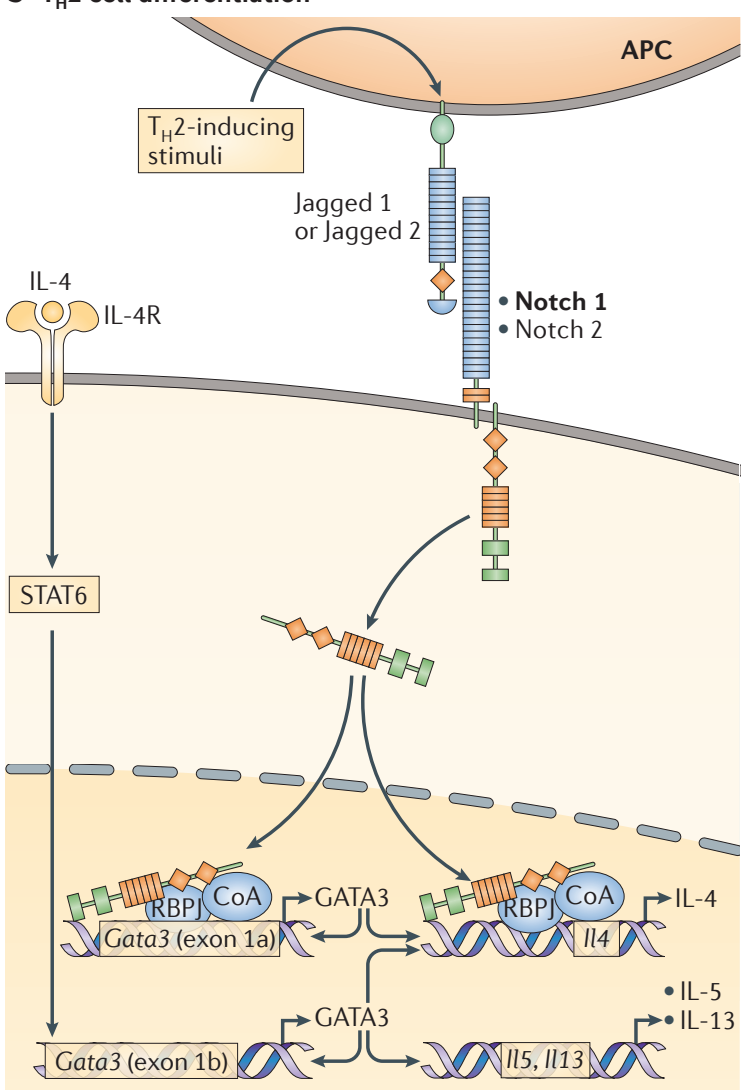

Figure 3 | Role of Notch in T helper 1 and T helper 2 cell differentiation and function. Thelper $\left(T_{H}\right)$ cell-promoting signals induce the expression of Notch ligands (Delta-like ligands (DLLs) or Jagged) on antigen-presenting cells (APCs). a $\mid T_{H} 1$ cell-promoting signals induce the expression of DLLs and the release of the Notch intracellular domain (NICD), which can bind to the nuclear factor- $\kappa B$ (NF- $\kappa B$ ) family proteins $p 50$ and $p 65$. In addition, the NICD can control the release of interferon- $\gamma(\mathrm{IFN} \gamma)$ either directly or indirectly. $\mathbf{b} \mid \mathrm{T}_{\mathrm{H}} 2$ cell-promoting signals induce the expression of Jagged ligands and the release of the NICD, which interacts with recombination signal-binding protein for immunoglobulin $\mathrm{kJ}$ region (RBPJ), converting it to a transcriptional activator. RBPJ recruits co-activators ( $\mathrm{CoAs}$ ) and the complex binds and transactivates the promoter of GATA binding protein 3 (GATA3), transcribing exon 1a. Interleukin-4 (IL-4) can also initiate $\mathrm{T}_{\mathrm{H}} 2$ cell differentiation by triggering signal transducer and activator of transcription 6 (STAT6), which induces the transcription of Gata3. Transcription of Gata3 exon $1 \mathrm{~b}$ is Notch independent. Gata3 and Il4 expression reinforce GATA3 expression. GATA3 modifies the conformation of the $I l 4, \| l 5$ and $/ 113$ loci, allowing their transcription. Notch 1 is the predominant pathway used (indicated in bold). Dashed arrows represent hypothetical pathways. IL-4R, IL-4 receptor.

Altogether, increasing evidence reveals that Notch signalling considerably influences the development of immune responses by acting on the differentiation or function of different $\mathrm{T}_{\mathrm{H}}$ subsets (FIG. 3). Better understanding of the mechanisms involved in these processes will allow the design of appropriate strategies to favour or prevent the development of a $\mathrm{T}_{\mathrm{H}}$ cell subset during pathologies in which these $\mathrm{T}$ cells have important roles.

\section{Notch and regulatory $\mathrm{T}$ cell functions}

$\mathrm{T}_{\text {Reg }}$ cells have important functions in the maintenance of peripheral self-tolerance and in the modulation of various polarized $\mathrm{T}_{\mathrm{H}}$ cell immune responses. There are two main types of $\mathrm{T}_{\mathrm{Reg}}$ cell: $\mathrm{T}_{\mathrm{Reg}}$ cells that develop in the thymus (thymic $\mathrm{T}_{\text {Reg }}$ cells) and $\mathrm{T}_{\mathrm{Reg}}^{\mathrm{Reg}}$ cells that develop in the periphery from naive $\mathrm{CD}^{+} \mathrm{T}$ cells (peripherally induced $\mathrm{T}_{\mathrm{Reg}}$ cells). Common features of $\mathrm{T}_{\mathrm{Reg}}$ cells are their expression of the transcription factor FOXP3 and their suppression or control of pro-inflammatory immune responses ${ }^{86}$.
The first indications that Notch signalling could be involved in $\mathrm{T}_{\mathrm{Reg}}$ cell function originated from studies showing that $\mathrm{CD} 4^{+}$splenic $\mathrm{T}$ cells positive for $\mathrm{CD} 25$, a molecule expressed by $\mathrm{T}_{\mathrm{Reg}}$ cells, express higher levels of Notch 3 receptor than do $\mathrm{CD} 4^{+} \mathrm{CD} 25^{-}$wild-type cells, and that transgenic expression of intracellular, constitutively active Notch 3 in T cells induced the accumulation of $\mathrm{T}_{\mathrm{Reg}}$ cells in the thymus and periphery, leading to protection against experimentally induced autoimmune diabetes in mice ${ }^{87}$. Further studies by this group reported that Notch 3 promoted the development of $\mathrm{T}_{\text {Reg }}$ cells and improved their suppressive activity by upregulating FOXP3 expression ${ }^{88,89}$. In a more physiological setting, $\mathrm{T}_{\text {Reg }}$ cell exposure to Jagged 2-expressing haematopoietic progenitors induced the activation of Notch 3 signalling and promoted the expansion of $\mathrm{T}_{\mathrm{Reg}}$ cells that could prevent disease onset in an experimental type 1 diabetes mode $\mathrm{l}^{90}$. Collectively, these studies indicate an important role for Notch signalling in the expansion of $\mathrm{T}_{\mathrm{Reg}}$ cells. 
Neutralization of DLL4 during the induction of EAE resulted in an increase in the number of peripherally induced $\mathrm{T}_{\mathrm{Reg}}$ cells with a corresponding decrease in disease severity ${ }^{91}$. The effect was specific to DLL4, as DLL1 blockade had no effect on $\mathrm{T}_{\mathrm{H}} 17$ and $\mathrm{T}_{\mathrm{Reg}}$ cell differentiation during $\mathrm{EAE}^{92}$. In addition, a more recent study showed that anti-DLL4 treatment prevented the development of, and even reverted, type 1 diabetes in nonobese diabetic (NOD) mice by inducing an increase in the number of DC-dependent de novo thymic $\mathrm{T}_{\text {Reg }}$ cells $^{93}$. Taken together, these results demonstrate an essential role for DLL4-mediated immune regulation in the control of both thymic $\mathrm{T}_{\text {Reg }}$ cell and peripherally induced $\mathrm{T}_{\text {Reg }}$ cell homeostasis, although mechanistic details remain to be elucidated. Blocking Notch ligands could be a strategy to selectively regulate $\mathrm{T}_{\mathrm{Reg}}$ cell proliferation. Increasing data suggest that the selective blocking of DLL4-mediated Notch signalling ameliorates multiple forms of experimental autoimmunity via the regulation of $\mathrm{T}_{\text {Reg }}$ cells (BOX 2).

Jagged-mediated Notch signalling is also important in the control of peripherally induced $\mathrm{T}_{\mathrm{Reg}}$ cell differentiation. TGF $\beta$ induces FOXP3 expression in peripheral naive $\mathrm{T}$ cells, allowing their differentiation into peripherally induced $\mathrm{T}_{\text {Reg }}$ cells ${ }^{62,94}$. A role for Notch signalling in peripherally induced $\mathrm{T}_{\text {Reg }}$ cell differentiation was first suggested by several experiments showing that overexpression of the Notch ligand Jagged 1 on APCs led to peripherally induced $\mathrm{T}_{\mathrm{Reg}}$ cell differentiation both in vitro and in $v i v o^{95,96}$. The peripheral induction of $\mathrm{T}_{\mathrm{Reg}}$ cells by Notch signalling was shown to involve the activation of FOXP3, the master transcription factor of $\mathrm{T}_{\mathrm{Reg}}$ cells. Notch 1 cooperates with SMAD3 (a mediator of TGF $\beta$ signalling) and RBPJ to activate FOXP3 transcription ${ }^{5,97}$.

\section{Box $2 \mid$ Notch and autoimmune disease}

Autoimmune diseases such as multiple sclerosis and type 1 diabetes arise from inappropriate immune responses against self antigens, leading to the selective destruction of particular cell types or tissues. These inappropriate immune responses involve both adaptive and innate immune cells. As Notch signalling is involved in the regulation of peripheral immune responses, multiple groups have investigated the outcome of manipulating Notch signalling in experimental autoimmune disorders. Experimental autoimmune encephalomyelitis (EAE) is a frequently used mouse model for multiple sclerosis ${ }^{117}$. This inflammation-mediated demyelination disease of the central nervous system (CNS) can be induced by immunization with myelin antigens, viral infection or transfer of autoreactive T cells. Genetic and pharmacological interference with Notch signalling, as well as administration of blocking antibodies against Notch receptors or Delta-like ligand 4 (DLL4), impeded progression of the disease, resulting in reduced clinical severity $74,75,84,91,92,118-119$. The mechanisms by which blockage of Notch signalling ameliorates EAE are not fully understood and require further investigation. Possibilities include impaired T helper $1\left(T_{H} 1\right)$-type and $T_{H} 17$-type immune responses ${ }^{91}$; impaired migration of antigen-specific $\mathrm{CD} 4^{+} \mathrm{T}$ cells to the $\mathrm{CNS}$ as a consequence of downregulation of chemokine receptors ${ }^{119}$; and/or promotion of regulatory $\mathrm{T}$ cell development ${ }^{91}$. Similar observations have been reported in a more recent study using non-obese diabetic (NOD) mice as a model for type 1 diabetes. In these mice, pancreatic $\beta$-cells are selectively destroyed through autoreactive T cells. Administration of DLL4-specific antibodies prevented the development of type 1 diabetes and in some cases even caused the reversion of already established disease by inducing de novo expansion of regulatory $T$ cells $s^{93}$. Taken together, these preclinical studies indicate that selective blocking of DLL4-mediated Notch signalling may ameliorate multiple forms of autoimmunity.
Accordingly, in vivo treatment of mice with $\gamma$-secretase inhibitors reduced the TGF $\beta$-mediated induction of FOXP3, decreased peripherally induced $\mathrm{T}_{\text {Reg }}$ cell development and maintenance, and led to the development of autoimmune hepatitis ${ }^{5}$. The importance of Notch signalling in ensuring sustained FOXP3 expression and maintenance of peripherally induced $\mathrm{T}_{\text {Reg }}$ cells was recently confirmed in human cells ${ }^{98}$. Pluripotent stem cells transduced with FOXP3 and co-cultured on Notch ligandexpressing stromal cells generated stable $\mathrm{T}_{\mathrm{Reg}}$ cells in vitro ${ }^{99}$, suggesting that this could be a strategy for producing stable $\mathrm{T}_{\text {Reg }}$ cells for therapeutic adoptive transfer.

Collectively, increasing experimental evidence demonstrates a crucial role for Notch signalling in the expansion of thymic $\mathrm{T}_{\mathrm{Reg}}$ cells, in the differentiation of peripherally induced $\mathrm{T}_{\mathrm{Reg}}^{\mathrm{Reg}}$ cells and in the maintenance of both of these $\mathrm{T}_{\mathrm{Reg}}$ cell populations. However, more direct loss-of-function experiments will be required to validate these conclusions.

\section{Notch, cytotoxic T cells and GVHD}

Notch signalling promotes cytotoxic T lymphocyte differentiation. Both $\mathrm{CD}^{+}$and $\mathrm{CD} 8^{+} \mathrm{T}$ cells are required to eliminate many intracellular pathogens. Upon recognition of antigens presented by MHC class I-expressing cells, naive $\mathrm{CD}^{+} \mathrm{T}$ cells multiply and differentiate into cytotoxic T lymphocytes (CTLs). Effector functions of CTLs include the secretion of IFN $\gamma$, the lysis of target cells using perforins and granzymes, and the induction of target cell apoptosis through FAS-FAS ligand (FASL) interactions. A role for Notch in the differentiation of $\mathrm{CD}^{+} \mathrm{T}$ cells is supported by several studies.

The ligation of Notch ligands was shown to affect the differentiation of CTLs. DLL1 ligation by Notch expressed on splenic $\mathrm{CD} 8^{+} \mathrm{T}$ cells changed their patterns of cytokine secretion, decreasing their production of IFN $\gamma$ and increasing their production of IL-10 (REF. 100). In addition, $\mathrm{CD}^{+} \mathrm{T}$ cells exposed to allogenic DCs transduced with DLL1 showed increased granzyme B production and lysed target cells more efficiently in vitro, suggesting that DLL1-induced signalling contributes to CTL differentiation in vivo ${ }^{101}$. DLL1 blockade similarly decreased the frequency of granzyme B-producing CTLs, and lower cytotoxic activity of $\mathrm{CD}^{+} \mathrm{T}$ cells was observed in a transplantation model ${ }^{102}$.

Notch 2 expression on $\mathrm{CD}^{+} \mathrm{T}$ cells was reported to promote CTL differentiation and to directly regulate granzyme B and perforin expression both in vitro and in vivo, demonstrating a crucial role for Notch signalling in $\mathrm{CD}^{+} \mathrm{T}$ cell cytotoxic responses. Notch 2 formed a complex with phosphorylated cyclic AMP-responsive element-binding protein 1 (pCREB1) and the transcriptional co-activator $\mathrm{p} 300$ on the granzyme $\mathrm{B}(\mathrm{Gzmb})$ promoter ${ }^{101}$. The same group later reported that Notch 2 signalling, but not Notch 1 signalling, was required for the generation of antitumour CTL responses ${ }^{103}$. Further indication for a role of Notch signalling in CTL effector functions was reported using $\gamma$-secretase inhibitor treatment, which blocked the expression of the T-box eomesodermin (EOMES) transcriptional factor, thus reducing perforin and granzyme B expression. 
Treatment with $\gamma$-secretase inhibitors did not affect the FAS-FASL interactions of CTLs. Notch 1 antisense (Notch1 AS) mice, which have reduced expression of Notch 1, also showed reduced EOMES, perforin and granzyme B expression, suggesting that Notch 1 signalling is involved in CTL differentiation ${ }^{104}$. The nature of the Notch receptor involved (Notch 1 or Notch 2) may vary depending on the experimental context. A recent study reported a role for Notch also in the generation and function of human $\mathrm{CD}^{+} \mathrm{T}$ cells, suggesting that its role in this particular subset of $\mathrm{T}$ cells is conserved ${ }^{105}$.

Collectively, these experiments show an important role for Notch signalling in the differentiation of functional CTLs. The implication of Notch signalling in the generation of memory $\mathrm{CD}^{+} \mathrm{T}$ cells has not been investigated yet and should be of interest.

Notch signalling in GVHD. More recent evidence also suggests a role for the Notch cascade in regulating graftversus-host disease (GVHD) following allogeneic bone marrow transplantation (allo-BMT). Patients with leukaemia and patients with lymphoma have to undergo allo-BMT in cases in which tumour cells cannot be eradicated by chemotherapy. The goal of allo-BMT is that transplanted donor $\mathrm{T}$ cells mediate graft-versus-tumour (GVT) activity and thereby kill the cancer cells. However, GVT activity is often associated with GVHD because donor $\mathrm{T}$ cells also react against normal host tissue. This represents one of the major complications of allo-BMT in patients with cancer. Although these patients can subsequently be treated with immunosuppressive drugs to decrease the risk of GVHD, it comes at the price of impairing GVT activity. Such patients have a higher risk of undergoing tumour relapse, which compromises their overall survival $^{106}$.

In this context, preclinical studies were used to evaluate the function of Notch signalling in T cells in mouse models of allo-BMT settings using genetic loss-offunction approaches. Expression of a dominant-negative form of MAML1 (which blocks canonical Notch signalling of all receptors) in donor T cells resulted in near complete protection from acute GVHD in multiple models of allo-BMT (including major antigen mismatched models, such as transplantation of $\mathrm{C} 57 \mathrm{Bl} / 6$ bone marrow into BALB/c hosts). More importantly, these Notch signalling-incompetent $\mathrm{T}$ cells retained cytotoxic and anti-leukaemic activity, leading to substantially improved overall survival of host animals challenged with a B cell-lineage lymphoma. The protection against GVHD in this experimental setting was not mediated by an overall immunosuppression, as the Notch-deficient alloreactive $\mathrm{T}$ cells exhibited normal in vivo proliferative responses ${ }^{107}$. However, T cells expressing the dominantnegative-MAML1 mutant or lacking RBPJ produced reduced levels of multiple inflammatory cytokines, including IFN $\gamma$, IL-4, IL-17, tumour necrosis factor and IL-2, compared with wild-type T cells. Interestingly, the levels of T-bet and EOMES, which are, respectively, master regulators of $\mathrm{T}_{\mathrm{H}} 1$ cell and effector $\mathrm{CD}^{+} \mathrm{T}$ cell differentiation, were unchanged in Notch signalling-deficient $\mathrm{T}$ cells ${ }^{107}$. This argues against a simple differentiation defect of helper or effector T cells as a consequence of loss of Notch signalling. A more recent study from the same group in which blocking antibodies were used revealed that the beneficial effect of inhibiting Notch signalling in models of GVHD is mediated via the specific blockade of Notch 1 and Notch 2 on the receptor side and DLL1 and DLL4 on the ligand side. Blockage of individual receptors and ligands revealed dominant effects for Notch 1 and DLL4. Importantly, the combined administration of DLL1-specific and DLL4-specific antibodies provided long-lasting protection against GVHD without any apparent gut toxicities, such as those observed using blocking antibodies against the Notch receptors. The protection correlated with the persistent expansion of $\mathrm{T}_{\mathrm{Reg}}$ cells ${ }^{108}$. Although the elucidation of the precise mechanism requires further investigation, the impressive effects of blocking Notch signalling in mouse models of GVHD indicate a strong potential for clinical translation.

In addition to the role of Notch in alloreactive T cells, recent work suggests that Notch signalling in DCs can also influence GVHD ${ }^{109}$. Ikaros is a transcriptional repressor that in some contexts functions as a negative regulator of Notch signalling ${ }^{110,111}$. Ikaros-deficient bone marrow chimaeras revealed an enhanced GVHD in multiple models of allo-BMT compared with control animals. Ikaros deficiency resulted in upregulation of multiple Notch receptors, ligands and Notch target genes in DCs. Allogeneic T cells proliferated more when co-cultured with Ikaros-deficient DCs compared with when they were co-cultured with wild-type DCs, but this increased proliferation was reverted following the treatment of T cells with $\gamma$-secretase inhibitors to block Notch signalling. More importantly, allogeneic Ikaros-deficient bone marrow chimaeras treated with $\gamma$-secretase inhibitors in vivo showed a significantly diminished GVHD pathology compared with vehicle-treated control chimaeras ${ }^{109}$. It remains to be investigated whether Notch signalling in wild-type DCs influences GVHD. However, taken together, these reports show that blocking Notch signalling ameliorates GVHD in allo-BMT models, whereas GVT activity is preserved.

\section{Conclusion and perspectives}

During the past decade the Notch cascade has emerged as an important regulator of multiple cell fate decisions and differentiation processes during the development and function of the haematopoietic system. Among the most well-established functions of Notch are its essential roles in the specification and maturation of T cells, as well as of MZB cells. For these two lymphoid lineages, the relevant receptor-ligand pairs have been identified by conditional genetic loss-of-function approaches. T cell lineage commitment and maturation is mediated by DLL4-Notch 1 interactions, and MZB cell development is mediated by DLL1-Notch 2 interactions. Both of these processes use canonical (that is, RBPJ-dependent) Notch signalling. More recently, a role for Notch during development and/or expansion of ILCs has been identified. The role of Notch in ILCs has been inferred from multiple studies through the requirement of DLL-expressing feeder cells to generate ILCs in vitro. However, conditional 
inactivation of RBPJ has clearly demonstrated that Notch signalling is required in vivo for the development and/or expansion of $\mathrm{NKp} 46^{+}$ILCs within the lamina propria of the intestine. Additional loss-of-function studies will be required in the future to establish the in vivo relevance of Notch in ILCs, as well as for elucidating the ligand-receptor interactions that are involved.

Genetic loss-of-function experiments also show an important role of Notch signalling in both $\mathrm{T}_{\mathrm{H}} 2$ cell differentiation and $\mathrm{T}_{\mathrm{H}} 1$ cell function. Experimentally, Jagged or DLL expression on APCs has been associated with $\mathrm{T}_{\mathrm{H}} 2$ cell and $\mathrm{T}_{\mathrm{H}} 1$ cell differentiation, respectively. Genetic, pharmacological and antibody-based blockage of specific ligands and receptors confirmed the role of DLL-mediated Notch signalling in $\mathrm{T}_{\mathrm{H}} 1$ cell function. Interestingly, this is a process that does not require canonical RBPJ-mediated signalling. By contrast, $\mathrm{T}_{\mathrm{H}} 2$ cell differentiation is dependent on canonical Notch signalling. It is still generally unknown how Jagged- and DLL-expressing APCs differ in their ability to induce Notch signals and how this translates into the differentiation of $\mathrm{T}_{\mathrm{H}}$ cells.

Pharmacological Notch inhibitors and more specific blocking antibodies for individual Notch receptors and ligands were originally developed for anticancer therapy. These tools are now also being explored in the context of preclinical investigations of autoimmune diseases and GVHD. In particular, blocking Notch using DLL4-specific antibodies ameliorated pathology in several experimental autoimmune disease models. Similarly, Notch blockade in allo-BMT significantly reduced GVHD while preserving GVT activity. Although the exact mechanisms underlying these promising observations are not clear, they open the door to exploring these tools in immunological disorders in a clinical setting. Thus, Notch is an attractive target not only for cancer therapy but also for modulating the immune system during other pathological conditions.
1. Morgan, T. H. The theory of the gene. Am. Nat. 51, 513-544 (1917)

2. Bray, S. J. Notch signalling: a simple pathway becomes complex. Nature Rev. Mol. Cell Biol. 7 678-689 (2006).

3. Kopan, R. \& Ilagan, M. X. G. The canonical Notch signaling pathway: unfolding the activation mechanism. Cell 137, 216-233 (2009).

4. Poellinger, L. $\&$ Lendahl, U. Modulating Notch signaling by pathway-intrinsic and pathway-extrinsic mechanisms. Curr. Opin. Genet. Dev. 18, 449-454 (2008).

5. Samon, J. B. et al. Notch 1 and TGF $\beta 1$ cooperatively regulate Foxp3 expression and the maintenance of peripheral regulatory T cells. Blood 112, 1813-1821 (2008).

This study shows that Notch 1 and TGF $\beta$ cooperate in the regulation of $T$ cells.

6. Heitzler, P. Biodiversity and noncanonical Notch signaling. Curr. Top. Dev. Biol. 92, 457-481 (2010).

7. Palomero, T. et al. NOTCH1 directly regulates c-MYC and activates a feed-forward-loop transcriptional network promoting leukemic cell growth. Proc. Nat Acad. Sci. USA 103, 18261-18266 (2006).

8. Weng, A. P. et al. c-Myc is an important direct target of Notch 1 in T-cell acute lymphoblastic leukemia/ lymphoma. Genes Dev. 20, 2096-2109 (2006).

9. Iso, T., Kedes, L. \& Hamamori, Y. HES and HERP families: multiple effectors of the Notch signaling pathway. J. Cell. Physiol. 194, 237-255 (2003).

10. Radtke, F. et al. Deficient T cell fate specification in mice with an induced inactivation of Notch 1 . Immunity 10, 547-558 (1999).

11. Han, H. et al. Inducible gene knockout of transcription factor recombination signal binding protein-J reveals its essential role in $T$ versus $B$ lineage decision. Int. Immunol. 14, 637-645 (2002).

12. Pui, J. C. et al. Notch 1 expression in early lymphopoiesis influences B versus $T$ lineage determination. Immunity 11, 299-308 (1999). References 10-12 are the first genetic loss-of-function and reciprocal gain-of-function studies demonstrating that canonical Notch 1 signalling is essential for T cell lineage commitment.

13. Koch, $U$ et al Subversion of the T/B lineage decision in the thymus by lunatic fringe-mediated inhibition of Notch-1. Immunity 15, 225-236 (2001).

4. Izon, D. J. et al. Deltex 1 redirects lymphoid progenitors to the $\mathrm{B}$ cell lineage by antagonizing Notch1. Immunity 16, 231-243 (2002).

15. Yun, T. J. \& Bevan, M. J. Notch-regulated ankyrinrepeat protein inhibits Notch 1 signaling: multiple Notch1 signaling pathways involved in T cell development. J. Immunol. 170, 5834-5841 (2003).

16. Maillard, I. et al. Mastermind critically regulates Notch-mediated lymphoid cell fate decisions. Blood 104, 1696-1702 (2004).

17. Wilson, A., MacDonald, H. R. \& Radtke, F. Notch 1-deficient common lymphoid precursors adopt a B cell fate in the thymus. J. Exp. Med. 194, 1003-1012 (2001)

18. Bell, J. J. \& Bhandoola, A. The earliest thymic progenitors for $T$ cells possess myeloid lineage potential. Nature 452, 764-767 (2008).
19. Wada, H. et al. Adult T-cell progenitors retain myeloid potential. Nature 452, 768-772 (2008).

20. Feyerabend, T. B. et al. Deletion of Notch 1 converts pro-T cells to dendritic cells and promotes thymic $B$ cells by cell-extrinsic and cell-intrinsic mechanisms. Immunity 30, 67-79 (2009).

21. Wendorff, A. A. et al. Hes 1 is a critical but contextdependent mediator of canonical Notch signaling in lymphocyte development and transformation. Immunity 33, 671-684 (2010).

22. Jaleco, A. C. et al. Differential effects of Notch ligands $\delta-1$ and Jagged-1 in human lymphoid differentiation. J. Exp. Med. 194, 991-1002 (2001).

23. Schmitt, T. M. \& Zuniga-Pflucker, J. C. Induction of $T$ cell development from hematopoietic progenitor cells by $\delta$-like-1 in vitro. Immunity 17, 749-756 (2002).

References 22 and 23 are the first studies showing that $\mathrm{T}$ cells can be generated in vitro from haematopoietic progenitors when grown on feeder cells expressing DLL1.

24. Hozumi, K. et al. $\delta$-like 4 is indispensable in thymic environment specific for $\mathrm{T}$ cell development. J. Exp. Med. 205, 2507-2513 (2008)

25. Koch, U. et al. $\delta$-like 4 is the essential, nonredundant ligand for Notch1 during thymic T cell lineage commitment. J. Exp. Med. 205, 2515-2523 (2008).

References 24 and 25 identified DLL4 as the physiological ligand for $\mathrm{T}$ cell lineage commitment.

26. Mohtashami, M. et al. Direct comparison of DII 1 and DII4-mediated Notch activation levels shows differential lymphomyeloid lineage commitment outcomes. J. Immunol. 185, 867-876 (2010).

27. Taghon, T., Yui, M. A., Pant, R., Diamond, R. A. \& Rothenberg, E. V. Developmental and molecular characterization of emerging $\beta$ - and $\gamma \delta$-selected pre-T cells in the adult mouse thymus. Immunity 24 53-64 (2006).

28. Van de Walle, I. et al. An early decrease in Notch activation is required for human TCR- $\alpha \beta$ lineage differentiation at the expense of TCR- $\gamma \delta$ T cells. Blood 113, 2988-2998 (2009).

29. Taghon, T. et al. Notch signaling is required for proliferation but not for differentiation at a welldefined $\beta$-selection checkpoint during human T-cel development. Blood 113, 3254-3263 (2009).

30. Yashiro-Ohtani, Y. et al. Pre-TCR signaling inactivates Notch 1 transcription by antagonizing E2A Genes Dev. 23, 1665-1676 (2009)

31. Pillai, S. \& Cariappa, A. The follicular versus margina zone B lymphocyte cell fate decision. Nature Rev. Immunol. 9, 767-777 (2009).

32. Balazs, M., Martin, F., Zhou, T. \& Kearney, J. Blood dendritic cells interact with splenic marginal zone $B$ cells to initiate T-independent immune responses. Immunity 17, 341-352 (2002)

33. Hozumi, K. et al. $\delta$-like 1 is necessary for the generation of marginal zone $B$ cells but not $T$ cells in vivo. Nature Immunol. 5, 638-644 (2004).

34. Saito, T. et al. Notch2 is preferentially expressed in mature $B$ cells and indispensable for marginal zone $B$ lineage development. Immunity 18, 675-685 (2003).

35. Tanigaki, K. et al. Notch-RBP-J signaling is involved in cell fate determination of marginal zone $B$ cells. Nature Immunol. 3, 443-450 (2002).

References 33-35 are genetic loss-of-function studies demonstrating that canonical DLL1-mediated Notch 2 signalling is essential for the generation of MZB cells.

36. Oyama, T. et al. Mastermind-1 is required for Notch signal-dependent steps in lymphocyte development in vivo. Proc. Natl Acad. Sci. USA 104, 9764-9769 (2007).

37. Wu, L., Maillard, I., Nakamura, M., Pear, W. S. \& Griffin, J. D. The transcriptional coactivator Maml1 is required for Notch2-mediated marginal zone B-cell development. Blood 110, 3618-3623 (2007).

38. Song, R. et al. Mind bomb 1 in the lymphopoietic niches is essential for $\mathrm{T}$ and marginal zone $\mathrm{B}$ cell development. J. Exp. Med. 205, 2525-2536 (2008).

39. Gibb, D R et al. ADAM10 is essential for Notch2-dependent marginal zone B cell development and CD23 cleavage in vivo. J. Exp. Med. 207, 623-635 (2010)

40. Kuroda, K. et al. Regulation of marginal zone B cell development by MINT, a suppressor of Notch/RBP-J signaling pathway. Immunity 18, 301-312 (2003).

41. Tan, J. et al. Lunatic and manic fringe cooperatively enhance marginal zone $B$ cell precursor competition for $\delta$-like 1 in splenic endothelial niches. Immunity 30 254-263 (2009)

42. Caton, M. L., Smith-Raska, M. R. \& Reizis, B. NotchRBP-J signaling controls the homeostasis of CD8 dendritic cells in the spleen. J. Exp. Med. 204 1653-1664 (2007).

43. Lewis, K. L. et al. Notch2 receptor signaling controls functional differentiation of dendritic cells in the spleen and intestine. Immunity 35, 780-791 (2011). References 42 and 43 are genetic loss-of function studies that show that RBPJ-mediated Notch 2 signalling controls the homeostasis of subsets of DCs in the spleen and intestine.

44. Radtke, F. et al. Notch1 deficiency dissociates the intrathymic development of dendritic cells and T cells. J. Exp. Med. 191, 1085-1094 (2000).

45. Ferrero, l. et al. Mouse CD $11 \mathrm{c}^{+} \mathrm{B} 220^{+} \mathrm{Gr} 1$ plasmacytoid dendritic cells develop independently of the T-cell lineage. Blood 100, 2852-2857 (2002).

46. Spits, H. \& Cupedo, T. Innate lymphoid cells: emergin insights in development, lineage relationships, and function. Annu. Rev. Immunol. 30, 647-675 (2012).

47. Spits, H. et al. Innate lymphoid cells - a proposal for uniform nomenclature. Nature Rev. Immunol. 13 145-149 (2013).

48. Spits, H. \& Di Santo, J. P. The expanding family of innate lymphoid cells: regulators and effectors of immunity and tissue remodeling. Nature Immunol. 12 21-27 (2011)

49. Cherrier, M., Sawa, S. \& Eberl, G. Notch, Id2, and ROR $\gamma$ t sequentially orchestrate the fetal development of lymphoid tissue inducer cells. J. Exp. Med. 209, 729-740 (2012) 
50. Satoh-Takayama, N. et al. Microbial flora drives interleukin 22 production in intestinal NKp46+ cells that provide innate mucosal immune defense. Immunity 29, 958-970 (2008).

51. Zheng, Y. et al. Interleukin-22 mediates early host defense against attaching and effacing bacterial pathogens. Nature Med. 14, 282-289 (2008).

52. Kiss, E. A. et al. Natural aryl hydrocarbon receptor ligands control organogenesis of intestinal lymphoid follicles. Science 334, 1561-1565 (2011).

53. Li, Y. et al. Exogenous stimuli maintain intraepithelial lymphocytes via aryl hydrocarbon receptor activation. Cell 147, 629-640 (2011).

54. Lee, J. S. et al. AHR drives the development of gut ILC22 cells and postnatal lymphoid tissues via pathways dependent on and independent of Notch. Nature Immunol. 13, 144-151 (2012).

This study showed that the development and/or expansion of NKp46+ ILCs in certain microenvironments is mediated by AHR-induced Notch signalling.

55. Buonocore, S. et al. Innate lymphoid cells drive interleukin-23-dependent innate intestinal pathology. Nature 464, 1371-1375 (2010)

56. Neill, D. R. et al. Nuocytes represent a new innate effector leukocyte that mediates type- 2 immunity. Nature 464, 1367-1370 (2010)

57. Price, A. E. et al. Systemically dispersed innate IL-13-expressing cells in type 2 immunity. Proc. Natl Acad. Sci. USA 107, 11489-11494 (2010).

58. Wong, S. H. et al. Transcription factor ROR $\alpha$ is critical for nuocyte development. Nature Immunol. 13 229-236 (2012)

59. Mosmann, T. R., Cherwinski, H., Bond, M. W., Giedlin, M. A. \& Coffman, R. L. Two types of murine helper T cell clone. I. Definition according to profiles of lymphokine activities and secreted proteins. J. Immunol. 136, 2348-2357 (1986).

60. Harrington, L. E. et al. Interleukin 17-producing $\mathrm{CD}^{+}{ }^{+}$effector $\mathrm{T}$ cells develop via a lineage distinct from the Thelper type 1 and 2 lineages. Nature Immunol. 6, 1123-1132 (2005).

61. Veldhoen, M., Hocking, R. J., Atkins, C. J., Locksley, R. M. \& Stockinger, B. TGF $\beta$ in the context of an inflammatory cytokine milieu supports de novo differentiation of IL-17-producing T cells. Immunity 24, 179-189 (2006)

62. Chen, W. et al. Conversion of peripheral $\mathrm{CD} 4{ }^{+} \mathrm{CD} 25^{-}$ naive $T$ cells to $C D 4+C D 25+$ regulatory $T$ cells by TGF- $\beta$ induction of transcription factor Foxp3. J. Exp. Med. 198, 1875-1886 (2003).

63. Veldhoen, M. et al. Transforming growth factor- $\beta$ 'reprograms' the differentiation of T helper 2 cells and promotes an interleukin 9-producing subset. Nature Immunol. 9, 1341-1346 (2008).

64. Dardalhon, V. et al. IL-4 inhibits TGF- $\beta$-induced Foxp $3+T$ cells and, together with TGF- $\beta$, generates IL-9+ IL-10+ Foxp3- effector T cells. Nature Immunol. 9, 1347-1355 (2008)

65. Johnston, R. J. et al. Bcl6 and Blimp-1 are reciprocal and antagonistic regulators of $\mathrm{T}$ follicular helper cell differentiation. Science 325, 1006-1010 (2009).

66. Nurieva, R. I. et al. Bcl6 mediates the development of T follicular helper cells. Science 325, 1001-1005 (2009).

67. O'Shea, J. J. \& Paul, W. E. Mechanisms underlying lineage commitment and plasticity of helper CD4 T cells. Science 327, 1098-1102 (2010).

68. Oestreich, K. J. \& Weinmann, A. S. Master regulators or lineage-specifying? Changing views on $\mathrm{CD}^{+} \mathrm{T}$ cell transcription factors. Nature Rev. Immunol. 12 799-804 (2012)

69. Amsen, D., Spilianakis, C. \& Flavell, R. How are $T_{H} 1$ and $\mathrm{T}_{\mathrm{H}} 2$ effector cells made? Curr. Opin. Immunol. 21 153-160 (2009).

70. Radtke, F., Fasnacht, N. \& Macdonald, H. R. Notch signaling in the immune system. Immunity 32, 14-2 (2010).

71. Auderset, F., Coutaz, M. \& Tacchini-Cottier, F. The role of Notch in the differentiation of $C D 4^{+} T$ helper cells. Curr. Top. Microbiol. Immunol. 360, 115-134 (2012).

72. Amsen, D. et al. Instruction of distinct CD4 T helper cell fates by different notch ligands on antigenpresenting cells. Cell 117, 515-526 (2004). This is the first study demonstrating that the stimulation of different Notch ligands triggers the differentiation of distinct $T_{H}$ cell subsets.

73. Amsen, D., Antov, A. \& Flavell, R. A. The different faces of Notch in T-helper-cell differentiation. Nature Rev. Immunol. 9, 116-124 (2009).

74. Minter, L. M. et al. Inhibitors of $\gamma$-secretase block in vivo and in vitro T helper type 1 polarization by preventing Notch upregulation of $T b \times 21$. Nature Immunol. 6, 680-688 (2005)

75. Jurynczyk, M., Jurewicz, A., Raine, C. S. \& Selmaj, K. Notch3 inhibition in myelin-reactive T cells downregulates protein kinase $C$ theta and attenuates experimental autoimmune encephalomyelitis. J. Immunol. 180, 2634-2640 (2008)

76. Fang, T. C. et al. Notch directly regulates Gata3 expression during T helper 2 cell differentiation. Immunity 27, 100-110 (2007).

77. Tu, L. et al. Notch signaling is an important regulator of type 2 immunity. J. Exp. Med. 202, 1037-1042 (2005).

78. Auderset, F. et al. Redundant Notch 1 and Notch2 signaling is necessary for IFN $\gamma$ secretion by $\mathrm{T}$ helper cells during infection with Leishmania major. PLoS Pathog. 8, e1002560 (2012).

This study shows that Notch regulates the function of $T_{H} 1$ cells but, together with reference 77 , it shows that this does not involve RBPJ-dependent Notch signalling.

79. Palaga, T., Miele, L., Golde, T. E. \& Osborne, B. A. TCR-mediated notch signaling regulates proliferation and IFN- $\gamma$ production in peripheral T cells. J. Immunol. 171, 3019-3024 (2003).

80. Shin, H. M. et al. Notch 1 augments NF-кB activity by facilitating its nuclear retention. EMBO J. 25 , 129-138 (2006)

81. Amsen, D. et al. Direct regulation of Gata3 expression determines the $T$ helper differentiation potential of Notch. Immunity 27, 89-99 (2007)

82. Tanaka, S. et al. The interleukin-4 enhancer CNS-2 is regulated by Notch signals and controls initial expression in NKT cells and memory-type CD4 T cells. Immunity 24, 689-701 (2006).

83. Zheng, W. \& Flavell, R. A. The transcription factor GATA-3 is necessary and sufficient for Th2 cytokine gene expression in CD4 T cells. Cell 89, 587-596 (1997) Together with reference 76, these studies [Au: Which studies?] show that Notch can regulate GATA3, one of the master regulators of $\mathrm{T}_{\mathrm{H}} 2$ cell differentiation.

84. Elyaman, W. et al. Notch receptors and Smad3 signaling cooperate in the induction of interleukin9-producing T cells. Immunity 36, 623-634 (2012).

85. Becher, B. $\&$ Segal, B. M. $T_{H} 17$ cytokines in autoimmune neuro-inflammation. Curr Opin. Immunol. 23, 707-712 (2011).

86. Campbell, D. J. \& Koch, M. A. Phenotypical and functional specialization of FOXP3 + regulatory T cells. Nature Rev. Immunol. 11, 119-130 (2011).

87. Anastasi, E et al. Expression of activated Notch3 in transgenic mice enhances generation of $\mathrm{T}$ regulatory cells and protects against experimental autoimmune diabetes. J. Immunol. 171, 4504-4511 (2003).

88. Campese, A. F. et al. Notch 3 and $\mathrm{pT} \alpha /$ pre-TCR sustain the in vivo function of naturally occurring regulatory T cells. Int. Immunol. 21, 727-743 (2009).

89. Barbarulo, A et al. Notch3 and canonical NF-кB signaling pathways cooperatively regulate Foxp3 transcription. J. Immunol. 186, 6199-6206 (2011)

90. Kared, H. et al. Jagged2-expressing hematopoietic progenitors promote regulatory $\mathrm{T}$ cell expansion in the periphery through notch signaling. Immunity $\mathbf{2 5}$ 823-834 (2006)

This study reveals that the expression of Jagged 2 on haematopoietic precursor cells promotes the differentiation of $\mathrm{T}_{\mathrm{Reg}}$ cells in the periphery.

91. Bassil, R. et al. Notch ligand $\delta$-like 4 blockade alleviates experimental autoimmune encephalomyelitis by promoting regulatory $\mathrm{T}$ cell development. J. Immunol. 187, 2322-2328 (2011)

92. Elyaman, W. et al. JAGGED 1 and $\delta 1$ differentially regulate the outcome of experimental autoimmune encephalomyelitis. J. Immunol. 179, 5990-5998 (2007).

93. Billiard, F. et al. DII4-Notch signaling in Flt3-independent dendritic cell development and autoimmunity in mice. J. Exp. Med. 209, 1011-1028 (2012)

94. Rao, P. E., Petrone, A. L. \& Ponath, P. D. Differentiation and expansion of $T$ cells with regulatory function from human peripheral lymphocytes by stimulation in the presence of TGF- $\beta$. J. Immunol. 174, 1446-1455 (2005)

95. Hoyne, G. F. et al. Serrate 1 -induced notch signalling regulates the decision between immunity and tolerance made by peripheral $\mathrm{CD} 4^{+} \mathrm{T}$ cells. Int. Immunol. 12, 177-185 (2000).

96. Vigouroux, S. et al. Induction of antigen-specific regulatory T cells following overexpression of a Notch ligand by human B lymphocytes. J. Virol. 77, 10872-10880 (2003)

97. Asano, N., Watanabe, T., Kitani, A., Fuss, I. J \& Strober, W. Notch 1 signaling and regulatory T cell function. J. Immunol. 180, 2796-2804 (2008).
98. Del Papa, B. et al. Notch1 modulates mesenchymal stem cells mediated regulatory T-cell induction. Eur. J. Immunol. 43, 182-187 (2012).

99. Haque, R. et al. Programming of regulatory T cells from pluripotent stem cells and prevention of autoimmunity. J. Immunol. 189, 1228-1236 (2012).

100. Wong, K. et al. Notch ligation by $\delta 1$ inhibits periphera immune responses to transplantation antigens by a $\mathrm{CD}^{+}$cell-dependent mechanism. J. Clin. Invest. 112 1741-1750 (2003).

101. Maekawa, Y. et al. Notch2 integrates signaling by the transcription factors RBP-J and CREB 1 to promote T cell cytotoxicity. Nature Immunol. 9, 1140-1147 (2008).

102. Riella, L. V. et al. Blockade of Notch ligand $\delta 1$ promotes allograft survival by inhibiting alloreactive Th 1 cells and cytotoxic T cell generation. J. Immunol. 187, 4629-4638 (2011)

103. Sugimoto, K. et al. Notch2 signaling is required for potent antitumor immunity in vivo. J. Immunol. 184, 4673-4678 (2010).

104. Cho, O. H. et al. Notch regulates cytolytic effector function in $\mathrm{CD}^{+}{ }^{+} \mathrm{T}$ cells. J. Immunol. 182 3380-3389 (2009).

105. Kuijk, L. M. et al. Notch controls generation and function of human effector CD8+ T cells. Blood 121 , 2638-2646 (2013).

106. Welniak, L. A., Blazar, B. R. \& Murphy, W. J. Immunobiology of allogeneic hematopoietic stem cell transplantation. Annu. Rev. Immunol. 25, 139-170 (2007).

107. Zhang, Y. et al. Notch signaling is a critical regulator of allogeneic $\mathrm{CD}^{+}{ }^{+} \mathrm{T}$-cell responses mediating graftversus-host disease. Blood 117, 299-308 (2011).

108. Tran, I. T. et al. Blockade of individual Notch ligands and receptors controls graft-versus-host disease. J. Clin. Invest. 123, 1590-1604 (2013). This study shows that blocking Notch signalling in donor T cells significantly reduces GVHD in mouse models of allo-BMT while preserving GVT activity.

109. Toubai, T. et al. Ikaros-Notch axis in host hematopoietic cells regulates experimental graftversus-host disease. Blood 118, 192-204 (2011).

110. Dumortier, A. et al. Notch activation is an early and critical event during T-cell leukemogenesis in lkarosdeficient mice. Mol. Cell. Biol. 26, 209-220 (2006).

111. Gomez-del Arco, P. et al. Alternative promoter usage at the Notch 1 locus supports ligand-independent signaling in T cell development and leukemogenesis. Immunity 33, 685-698 (2010).

112. Wolfe, M. S. $\gamma$-secretase inhibitors as molecular probes of presenilin function. J. Mol. Neurosci. 17, 199-204 (2001).

113. Haltiwanger, R. S. \& Stanley, P. Modulation of receptor signaling by glycosylation: fringe is an $O$-fucose- $\beta 1,3$ $\mathrm{N}$-acetylglucosaminyltransferase. Biochim. Biophys. Acta 1573, 328-335 (2002).

114. Bruckner, K., Perez, L., Clausen, H. \& Cohen, S. Glycosyltransferase activity of Fringe modulates Notch- $\delta$ interactions. Nature 406, 411-415 (2000).

115. Yang, L. T. et al. Fringe glycosyltransferases differentially modulate Notch 1 proteolysis induced by $\delta 1$ and Jagged1. Mol. Biol. Cell 16, 927-942 (2005)

116. Besseyrias, V. et al. Hierarchy of Notch- $\delta$ interactions promoting $\mathrm{T}$ cell lineage commitment and maturation. J. Exp. Med. 204, 331-343 (2007)

117. Baxter, A. G. The origin and application of experimental autoimmune encephalomyelitis. Nature Rev. Immunol. 7, 904-912 (2007).

118. Takeichi, N. et al. Ameliorating effects of anti-DII4 $\mathrm{mAb}$ on Theiler's murine encephalomyelitis virusinduced demyelinating disease. Int. Immunol. 22 729-738 (2010)

119. Reynolds, N. D., Lukacs, N. W., Long, N. \& Karpus, W. J. $\delta$-like ligand 4 regulates central nervous system $T$ cell accumulation during experimental autoimmune encephalomyelitis. J. Immunol. 187 2803-2813 (2011)

\section{Acknowledgements}

The work in the authors' laboratory is supported in part by the Swiss National Science foundation, the Swiss Cancer League and OptiStem.

Competing interests statement

The authors declare no competing financial interests.

FURTHER INFORMATION

Freddy Radtke's homepage: http://radtke-lab.epfl.ch

Fabienne Tacchini-Cottier's homepage:

http://www.unil.ch/ib/page9491 en.htm

ALL LINKS ARE ACTIVE IN THE ONLINE PDF 